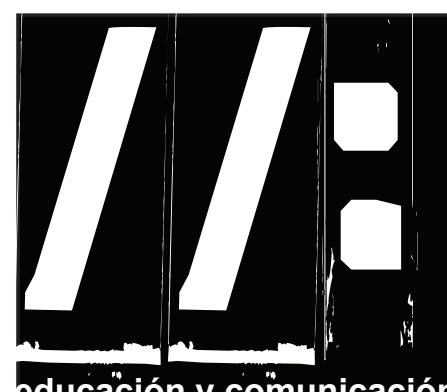

\title{
Alicia Gómez Montano
}

educación y communicación

18: 141-152 Mayo 2019

El perfil:

W adrileña y periodista, ha sido directora del 1 veterano programa de la RTVE "Informe Semanal" desde 2004 a 2012. Doctora en ciencias de la información y profesora universitaria. Persona comprometida con la profesión y es desde 2017 vicepresidenta de la sección española de Reporteros sin Fronteras.

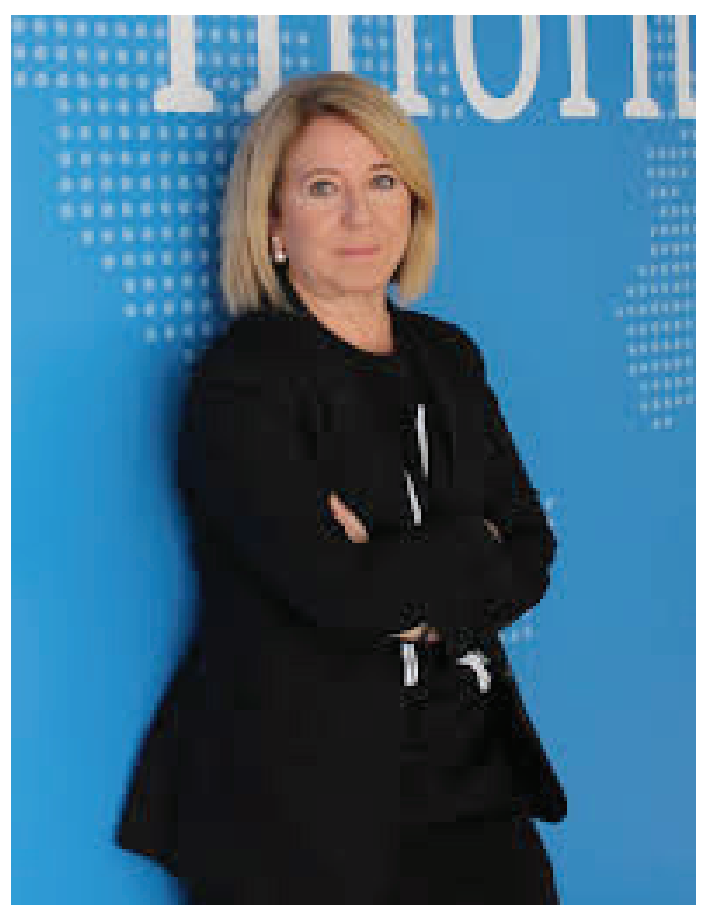




\section{II: Feminismo y medios de comunicación}

\section{1) ¿Qué es para usted el feminismo?}

Para mí el feminismo es un principio de igualdad de derechos entre la mujer y el hombre. No lo digo yo. Lo dice la RAE, pero comparto esta definición simple y concluyente. No tiene sentido que la mitad de la población mundial esté en una situación subordinada respecto a los varones. Pongo el énfasis en destacar que mientras el feminismo no va contra nadie y sólo reclama igualdad, el machismo es la actitud de prepotencia de los hombres respecto a las mujeres. Se trata, según la RAE, de un conjunto de prácticas, comportamientos y dichos que resultan ofensivos contra el género femenino.

2) ¿Cree que el concepto de feminismo, y lo que ello engloba, es entendido y aceptado por la sociedad actual?

No es bien entendido todavía. Mucha gente cree que el feminismo es el machismo de las mujeres y, como ya he explicado en la pregunta anterior, no son conceptos equiparables. Porque el feminismo no busca la supremacía, sino la igualdad.

3) ¿Qué papel juega la educación en el feminismo?

Es fundamental. La educación genera valores y hace que la sociedad sea más igualitaria. Educación en la escuela y también a través de los medios de comunicación que son claves para interpretar la realidad.

4) ¿Cree que en los medios de comunicación hay machismo?
Sí. Hay un lenguaje machista que a veces ni siquiera detectamos; hay una selección machista de los personajes que aparecen en los medios (los expertos suelen ser hombres) y hay muchos contenidos que no tienen perspectiva de género, porque las mujeres no están en una posición de liderazgo y no intervienen en la toma de decisiones.

\section{5) ¿Ha experimentado o ha visto alguna si- tuación de machismo en su profesión?}

Muchas. La televisión es un medio muy cruel. A una periodista se le dice muchas veces "qué guapa has salido". A un hombre, "qué bien has estado en el directo". No se aceptan órdenes de mujeres con la misma naturalidad que se aceptan de los hombres. A la mujer se la estigmatiza y es objeto de burlas (escondidas muchas veces) cuando ocupa un puesto de responsabilidad.

Personalmente, todavía recuerdo cuando tras un atentado en Pamplona, donde trabajaba, intenté mandar una pieza a Madrid por la noche y como no estaba el director no se envió porque el técnico de sonido me dijo que él no aceptaba órdenes de una mujer y menos si era bajita.

6) ¿Cree que desde que usted comenzó su carrera profesional al momento actual ha habido avances en igualdad de género en los medios de comunicación? ¿Cuáles?

Ha habido muchos avances: La mujer ha ido ocupando puestos clave, aunque la pirámide de mando siga siendo masculina; ha entrado en áreas de contenidos tradicionalmente masculinizadas y ha sido un referen- 


\section{1/: Alicia Gómez Montano}

te a la hora de impulsar contenidos que fomenten la igualdad y contribuyan a eliminar la desigualdad de géneros que existe.

7) ¿Cómo entiende usted la evolución del feminismo en los medios de comunicación?

Ha sido paulatina aunque ahora se ha producido una aceleración, porque el tsunami feminista y la actitud de las mujeres periodistas han hecho su efecto. Ahora hay conciencia de lo que somos y esa concienciación nos ha unido en una causa común. Y no quiero olvidarme de muchos hombres que están a nuestro lado.

8) ¿Cuál considera que ha sido el hito más importante del movimiento feminista?

Sin duda, la lucha por el derecho al voto. Ese fue el origen del cambio de un modelo patriarcal que sigue instalado, pero que tiene fecha de caducidad. Ha habido muchas donde las mujeres se han dejado la piel, pero con el voto se transformaron en ciudadanas de pleno derecho. Fue el primero y puede que el hito más importante.

9) Destacaría a alguna mujer, en el ámbito de los medios de comunicación, que le haya impactado por la defensa a la mujer y la igualdad de género.

Hay muchas. Entre las históricas destacaría a Carmen Sarmiento, a Rosa Calaf, a Georgina Cisquella y a Mercedes Milá, Teresa Santos (RNE Málaga)..., $\mathrm{Y}$ entre las nuevas generaciones a Carolina Pecha-

\section{Entrevista}

rromán, Magda Bandera (La Marea); Pilar Álvarez (El País); Ana Requena (Diario.es) Mariola Lourido (SER) etc...Y por supuesto, al colectivo de Mujeres de RTVE.

10) ¿Cuáles considera que son los principales puntos de desigualdad de género en los medios de comunicación?

La brecha salarial; la escala de mando llena de corbatas todavía y la falta de medidas que permitan la conciliación familiar y el reparto real de cargas entre hombres y mujeres.

11) ¿Cree que hay un periodismo de hombres y para hombres y uno de mujeres para mujeres?

El periodismo es el mismo para hombres o mujeres. El género no determina casi ninguna profesión y la de periodista tampoco. Es cierto que durante años ha habido una cierta especialización: por ejemplo, deporte para los hombres; moda y vida social para las mujeres. Pero estas barreras se han roto y el cambio es irreversible.

12) Es usted optimista o pesimista respecto a una igualdad de género real tanto en la sociedad como en los medios de comunicación.

Soy optimista, porque no se puede ir contra la historia y aunque pueda haber retrocesos y aunque haya intentos de demonización del feminismo, la fuerza de las mujeres de toda clase y condición es superior. Lo 


\section{IIA Feminismo y medios de comunicación}

hemos demostrado este 8 de marzo, el anterior y lo seguiremos demostrando. Nuestra fuerza es imparable.

13) Un deseo para esto del feminismo, los medios de comunicación y la educación

Un mundo más igualitario será necesariamente un mundo mejor. Por eso deseo que la brecha de desigualdad en el mundo se cierre mucho antes de esos 100 años que los expertos pronostican como plazo para alcanzar la igualdad real.

Espero que los medios de comunicación estén a la altura del reto que tienen por delante; que utilicen un lenguaje que no invisibilice a los mujeres y que piensen en contenidos que fomenten la igualdad y representen al conjunto de la sociedad.

En cuanto a la educación, es la piedra angular de la igualdad: educación en la escuela y en el hogar. Los niños repiten lo que ven y lo que oyen.

14) Disculpe, por último. Y si le dijera: -"Es que soy un caballero con las mujeres". ¿Qué me responderías?

Depende del contexto. Probablemente me reiría y te diría que me parece muy bien pero que no sé muy bien qué significa hoy ser un caballero y que no necesito que me abran la puerta del coche o el paraguas. Pero que tampoco hago asco a costumbres algo anticuadas, si vienen de alguien con buena voluntad.

\author{
Algunas preguntas cortas para responder con un \\ porqué: \\ Un libro: Cien años de soledad. Gabriel García Már- \\ quez \\ Una película: La vida de Brian \\ Un entretenimiento: viajar con los ojos muy abiertos. \\ Una pintura: El jardín de las delicias de El Bosco \\ Un museo: El Prado \\ Una canción: Purple Rain (Prince) \\ Una ciudad: Vancouver \\ Un mito: Medea \\ Un valor: la honestidad \\ Un personaje de la historia: Hipatia
}

